\title{
THE FORMATION OF THE RANGE CONCEPT THE FUNCTIONAL BREAD OF MASS RANGE
}

\author{
Irina N. Pushmina ${ }^{*}$, Olga Y. Kolman ${ }^{1}$, Irina N. Koyupchenko ${ }^{1}$, Mihail D. Kudryavtsev ${ }^{1,2,3}$ \\ ${ }^{1}$ Siberian Federal University, Krasnoyarsk, Russian Federation \\ ${ }^{2}$ Siberian State University of Science and Technology named after academician M.F. Reshetnev, \\ Krasnoyarsk, Russian Federation \\ ${ }^{3}$ Siberian Law Institute of the Ministry of Internal Affairs of Russia, \\ Krasnoyarsk, Russian Federation
}

\begin{abstract}
Determination of the directions of formation of the contemporary level of quality and assortment concept of the species diversity of functional bread of mass assortment with the use of wild berry plants Ericaceae for health improving nutrition. The materials were questionnaires of a survey of potential consumers of functional bread of the city of Krasnoyarsk, wild berry plants of the Heather family (Ericaceae): fruits of cranberry (Vaccinium oxycoccos), of cowberry (Vaccinium vitis-idaea), of bilberry (Vaccinium myrtillus), of blueberry (Vaccinium uliginosum) and powders from them. The method of isolation of the average sample according to GOST 24.027.0-80 was used in the work. The content of toxic elements in berries was determined according to GOST 26927-86, GOST 26930-86, GOST 30178-96 using an atomic emission spectrometer with inductively coupled plasma-iCAP 6500. Generally accepted theoretical and statistical research methods, combinatorial analysis, and data processing using standard mathematical programs were used in the work. Study of the consumer survey, literature data of the chemical composition of berries of wild plants Ericaceae, data on the possibility of procurement of raw materials on the territory of Krasnoyarsk region, investigation of safety performance of the raw material and powders out of him for compliance with the requirements of TR CU 021/2011 and 027/2012 indicate the possibility of their use in the composition of functional bread as a source of biologically active compounds with a variety of positive physiological properties. The multivariance of the development of the range of functional types of bread with additives from Ericaceae berries is confirmed by the data of combinatorial analysis. As a result, an assortment concept of the species diversity of functional bread of a mass assortment of contemporary quality with additives from wild berry plants Ericaceae for improving nutrition was formed. Researches is promising in the formation of the range and actual quality of functional types of bread of mass assortment using local wild-growing raw materials, the advantage of which is naturalness, the content of functional ingredients, and contribute to the development of the range and technologies of healthy food products.

Key words: econsumer preferences, fruits of cranberry (Vaccinium oxycoccos), fruits of cowberry (Vaccinium vitis-idaea), fruits of bilberry (Vaccinium myrtillus), fruits of blueberry (Vaccinium uliginosum), powders from dried berry, Toxicological safety, functional bread of mass assortment, contemporary level of quality, assortment concept.
\end{abstract}

Citation: Pushmina, I. N., Kolman, O. Y., Koyupchenko, I. N. \& Kudryavtsev, M. D. (2021). The formation of the range concept the functional bread of mass range. Trade, service, food industry. Vol. 1(1). Pp. 64-79.

\footnotetext{
(C) Siberian Federal University. All rights reserved

* Corresponding author E-mail address: root1986@mail.ru

ORCID ID: 0000-0003-3783-3535 (Pushmina), 0000-0002-3860-7209 (Kolman), 0000-0569-5132-4000

(Koyupchenko), 0000-0002-2432-1699 (Kudryavtsev)
} 


\title{
ФОРМИРОВАНИЕ АССОРТИМЕНТНОЙ КОНЦЕПЦИИ ФУНКЦИОНАЛЬНОГО ХЛЕБА МАССОВОГО АССОРТИМЕНТА \\ Ирина Николаевна Пушмина ${ }^{1}$, Ольга Яковлевна Кольман ${ }^{1}$, Ирина Николаевна Коюпченко ${ }^{1}$, Михаил Дмитриевич Кудрявцев ${ }^{1,2,3}$ \\ ${ }^{1}$ ФГАОУ ВО «Сибирский федеральный университет», \\ Красноярск, Российская Федерация \\ ${ }^{2}$ ФГБОУ ВО «Сибирский государственный университет науки и технологий им. академика М.Ф. Решетнева», Красноярск, Российская Федерация \\ ${ }^{3}$ ФГКОУ ВО «Сибирский юридический институт МВД России», Красноярск, Российская Федерация
}

\begin{abstract}
Аннотация. Определение направлений формирования актуального уровня качества и ассортиментной концепции видового разнообразия функционального хлеба массового ассортимента с использованием ягодных дикоросов Ericaceae для оздоровления питания. Материалами являлись анкеты опроса потенциальных потребителей функционального хлеба города Красноярска, ягодные дикоросы семейства вересковых (Ericaceae): плоды клюквы (Vaccinium oxycoccos), брусники (Vaccinium vitis-idaea), черники (Vaccinium myrtillus), голубики (Vaccinium uliginosum) и порошки из них. В работе применяли метод выделения средней пробы по ГОСТ 24.027.0-80. Содержание токсичных элементов в ягодах определяли по ГОСТ 26927-86, ГОСТ 26930-86, ГОСТ 30178-96 с использованием атомно-эмиссионного спектрометра с индуктивно связанной плазмой - iCAP 6500. Методы исследования: комбинаторный анализ, методы математической статистики. Изучение опроса потребителей, литературных данных химического состава ягодных дикоросов Ericaceae, данных о возможности заготовки этого сырья на территории Красноярского края, исследование показателей безопасности данного сырья и порошков из него на соответствие требованиям ТР ТС 021/2011 и 027/2012 свидетельствуют о возможности их использования в составе функционального хлеба как источник биологически активных соединений с разнообразными позитивными физиологическими свойствами. Многовариантность развития ассортимента функциональных видов хлеба с добавками из ягод Ericaceae подтверждено данными комбинаторного анализа. В результате сформирована ассортиментная концепция видового разнообразия функционального хлеба массового ассортимента актуального качества с добавками из ягодных дикоросов Ericaceae для оздоровления питания. Исследования носят перспективный характер в формировании ассортимента и актуального качества функциональных видов хлеба массового ассортимента с использованием местного дикорастущего сырья, преимущество которых - натуральность, содержание функциональных ингредиентов, и вносят вклад в развитие ассортимента и технологий продуктов здорового питания.
\end{abstract}

Ключевые слова: потребительские предпочтения, плоды клюквы (Vaccinium oxycoccos), плоды брусники (Vaccinium vitis-idaea), плоды черники (Vaccinium myrtillus), плоды голубики (Vaccinium uliginosum), порошки из сушеных ягод, токсикологическая безопасность, функциональный хлеб массового ассортимента, актуальный уровень качества, ассортиментная концепция.

Введение. Статус питания напрямую влияет на показатели здоровья человека. Постоянные нарушения и дефицит пищевых веществ в питании отрицательно сказываются на состоянии здоровья различных групп населения, провоцируя возникновение алиментарнозависимых заболеваний, тем самым существенно снижая статус здоровья человека и качество его жизни в целом $[1,2]$.

Согласно признанной мировой наукой совокупности теоретических и методологических положений теории адекватного (видового) питания, парадигмы питания академика А.М. Уголева, питание человека должно соответствовать современному образу 
жизни человека. Правильное питание является важной и неотъемлемой частью здорового образа жизни человека [1].

Хлеб как продукт ежедневного и массового потребления является существенным фактором влияния на внутреннюю среду организма человека. В связи с этим, качество, потребительские характеристики хлеба имеют большое значение и должны формироваться в направлении повышения его пищевой ценности, придания функциональных свойств, включая профилактические, а также свойств продуктов из категории «суперфуд» («superfood») в сочетании с высокими вкусовыми качествами [1, 3-8].

В соответствии со Стратегией национальной безопасности Российской Федерации до 2020 г., утвержденной Указом Президента Российской Федерации от 12 мая 2009 г. № 537, необходимо обеспечить потребителей разнообразными продуктами [9]. В программе «Основы государственной политики в области здорового питания населения на период до 2020 г.» поставлены такие приоритетные задачи, как «разработка и производство обогащенных специализированных продуктов для массового питания населения, в том числе с использованием функциональных ингредиентов из растительного сырья и направленных на профилактику заболеваний, оздоровление нации» [10].

Важно отметить, - в современном обществе пришло постепенно понимание того, что процесс вытеснения отечественного товаропроизводителя натуральных пищевых продуктов с продовольственного рынка страны и замещение их продуктами с синтетическими наполнителями и добавками различного состава и свойств, подвергает большому риску здоровье и социальную стабильность российского общества [11-13]. В пищевой индустрии применяют более трех тысяч синтетических соединений для формирования потребительских свойств продукции (консерванты, улучшители вкуса, текстуры; ароматизаторы, красители и тому подобное). Синтетические вещества, задерживаясь в организме человека, нарушают обмен веществ, приводят к дефициту витаминов, других биологически активных веществ, хронической экзогенной интоксикации организма, запуская механизм образования эндотоксинов и развития серьезных патологий $[14,15]$.

Очень важно в современных условиях повысить пищевую ценность продукции хлебопекарного производства с высоким содержанием пищевых волокон [5-8, 16, 17]. По словам А.М. Уголева «...рафинированные пищевые продукты... служат причиной многих серьезных заболеваний» [1]. Недостаточное количество пищевых волокон может привести к серьезным заболеваниям [1. 2, 14, 15].

В настоящее время требуется внедрять на потребительский рынок различные наполнители и добавки, включая продукты переработки дикорастущего растительного сырья $[5,6,9-12,18,19]$.

Дикорастущие пищевые и лекарственно-технические растения являются ценными источниками получения функциональных ингредиентов для их дальнейшего использования и для ежедневного и массового употребления [8, 20-27].

Значительную долю в общем объеме дикорастущего и лекарственно-технического растительного сырья, заготавливаемого в европейских странах, в России, том числе и в Сибирском регионе, занимают ягоды семейства вересковых [8, 25, 27-29].

Большинство растений семейства вересковых кустарники или кустарнички, иногда травы, в том числе сапрофитные [25, 27, 28]. Ягоды семейства вересковых (клюква, брусника, черника, голубика) богаты биологически активными веществами и минорными компонентами пищи, традиционно используются в питании населения, включая жителей Сибирского региона [30-34].

Напряженная экологическая обстановка большинства регионов Российской Федерации, Сибирский регион не является исключением, обязывает осуществлять сбор дикорастущего пищевого и лекарственно-технического сырья на территориях, признанных зонами экологического благополучия [35-37], а также диктует необходимость проводить исследования на подтверждение токсикологической безопасности растительного сырья [3638]. 
Современные особенности жизни подавляющего большинства населения влияют на интерес и предпочтения потребителей к пищевым продуктам различных товарных групп [39, 40]. Осуществить оперативное получение первичных сведений с целью выявления мнения, интереса и предпочтений потребителей возможно с использованием проведения социологического опроса методом анкетирования [39-42].

Целью представленных исследований явилось определение направлений формирования актуального уровня качества и ассортиментной концепции видового разнообразия функционального хлеба массового ассортимента для оздоровления питания населения на основании изучения данных социологического опроса потенциальных потребителей, анализа пищевой ценности, токсикологической безопасности плодовоягодных дикоросов семейства вересковых и данных комбинаторного анализа. Для этого необходимо:

1) произвести сбор и обработку первичной информации результатов социологического опроса (анкет-вопросников) для выявления предпочтений потенциальных потребителей хлеба функционального назначения;

2) оценить пищевую ценность и потребительские свойства ягод семейства вересковых (клюквы, брусники, черники, голубики) и с целью выбора экологически благоприятных территорий для сбора указанных ягод изучить результаты данных соответствующих государственных структур по Красноярскому краю;

3) провести поиск и определить лучшие плодово-ягодные наполнители для хлебной продукции, изучить их гигиеническую безопасность;

4) основываясь на полученных данных и данных комбинаторного анализа спрогнозировать направления формирования актуального уровня качества и ассортиментной концепции видового разнообразия функционального хлеба массового ассортимента для оздоровления питания населения.

Материалы и методы. Материалами исследования являлись: анкеты социологического опроса потенциальных потребителей хлеба функционального назначения, ягодные дикоросы семейства вересковых (лат. Ericaceae): клюква, брусника, черника, голубика.

Анкеты для проведения социологического опроса потребителей подготавливались заранее и имели вид опросной формы со спланированным перечнем интересующих вопросов открытого типа и вариантами ответов. Причем в вопросах, допускающих дискуссионную вариативность, для респондентов возможен выбор с одним или несколькими вариантами ответов соответствующего содержания на один и тот же вопрос и так же предусмотрен ответ «Ваш вариант».

Социологические исследования по выявлению предпочтений потенциальных потребителей функционального хлеба были выполнены путем определения выборочной совокупности (квотный отбор) и последующего опроса среди населения г. Красноярска [43, 44].

Для проведения эксперимента использовались плоды клюквы (лат. Vaccinium oxycoccos L.), брусники (лат. Vaccinium vitis-idaea L.), черники (лат. Vaccinium myrtillus L.), голубики (лат. Vaccinium uliginosum L.). Работы по сбору ягод проводились в Шушенском, Енисейском и Канском районах Красноярского края. По данным Главного управления природных ресурсов и охраны окружающей среды Министерства экологии и рационального природопользования Красноярского края на 01.01.2020 года указанная местность считается экологически достаточно благополучной [35-37].

Проверка и выбор ягод для исследований выполнялись путем выделения средней пробы методом квартования по ГОСТ 24.027.0-80. Допустимые отклонения в массе средней пробы плодово-ягодного сырья, в соответствии с ГФХІ, не превышали $\pm 10 \%$ [45].

Токсикологические исследования ягодной продукции определяли по ГОСТ 26927-86, ГОСТ 26930-86, ГОСТ 30178-96 с помощью атомно-эмиссионного спектрометра с индуктивно связанной плазмой - іСАР 6500 [46]. 
Дополнительно при проведении исследований использовали сравнение, синтез, анализ, индукцию, обобщение и систематизацию полученных результатов, а также комбинаторный анализ и методы математической статистики. [47, 48].

Обсуждение. При выработке подходов к формированию качества функционального хлеба как продукта здорового питания, его видовому разнообразию, ассортименту основывались на положении научной теории адекватного питания академика А.М. Уголева, согласно которому общие эволюционно-физиологические особенности, темпоритм жизни современного индивида обуславливают его о потребность в пище с добавленной пользой, имеющей вид и форму удобную для потребления [1]. Создавая концепцию, профиль актуального хлебного изделия ежедневного и массового ассортимента, исходили из данного положения, учитывая потребности и предпочтения современного индивида, как потенциального потребителя данного продукта, путем проведения социологического опроса и анализа его результатов.

Современный потребитель все чаще делает выбор в пользу наполнителей, добавок, ингредиентов, полученных из натурального растительного сырья, и которые потенциально можно вводить в рецептуру хлеба для повышения его пищевой ценности, расширения вкусового спектра, придания функциональных свойств $[8,13,39]$ и свойств продукта «суперфуд» [7].

Ориентация на потребителя - основной и эффективный принцип контроля над продукцией в соответствии с Международными стандартами ИСО [42]. Также и при формировании качества и видового разнообразия хлеба однозначно важно знать мнение потенциальных потребителей продукции и ориентироваться на него в принятии композиционных решений новых продуктов [26, 39, 41].

На современном потребительском рынке хлебобулочных изделий представлен довольно широкий ассортимент хлеба с различными добавками и из различных видов муки, но в то же время практически отсутствуют хлебные изделия с бикомпонентными и поликомпонентными добавками из ягод семейства вересковых и продуктов их переработки. Природный комплекс биологически активных веществ, включая природные антиоксиданты и антисептические вещества, ягод клюквы, брусники, черники, голубики при их введении в хлебные изделия обуславливает эффект обогащения, добавленной пользы и увеличение срока сохранения свежести готовых изделий.

Гипотезой предполагается на основании анализа опроса по выявлению предпочтений потребителей, а также анализа химического состава, исследования токсикологической безопасности широко распространенного дикорастущего плодово-ягодного сырья и комбинаторного анализа определить направления актуального развития качества, повышения пищевой ценности и формирования ассортиментной концепции видового разнообразия функционального хлеба массового ассортимента для оздоровления питания населения.

Полученные результаты. Для достижения поставленной в работе цели и определения объекта дальнейшего исследования в период с октября по декабрь 2019 г. был проведен социологический опрос, направленный на изучение потребительских предпочтений жителей города Красноярска к хлебной продукции, изготовленной с использованием поликомпонентных ингредиентов. Участники опроса - 500 человек от 20 лет и старше. Опрос населения проводился в предприятиях розничной торговли в г. Красноярске по анкетам. Опрос был выполнен на основании квотного отбора по основным параметрам. Выполнено вычисление квот по социально-демографическим позициям населения [43, 44]. В исследовании достигнуто соответствие квотированного соотношения выборочной совокупности таковому в генеральной совокупности, - получены результаты, по которым можно ориентироваться на предпочтения всех жителей Красноярска. Статистическая погрешность - не более 4,50\% при доверительной вероятности 95\%. Это так же свидетельствует о переносе выявленных итогов опроса на все население города Красноярска в целом с высокой степенью достоверности. 
Было опрошено 500 человек, из которых 270 женщин (54\%) и 230 мужчин (46\%). Участники опроса с высшим и незаконченным высшим образованием - 29,5\%, со средним профессиональным - 33,9\%, средним полным и начальным профессиональным - 22,0\%, основным и начальным - $14,6 \%$.

Часть респондентов не имеют достаточных сведений о функциональной хлебной продукции (рис. 1). В связи с этим, у части населения формируется особое отношение к хлебным продуктам, граничащее с безусловной разочарованностью в актуальном качестве традиционного или нового продукта функциональной направленности. Между тем, большинство опрошенных (63\%) выразили однозначный интерес и потребительскую лояльность к функциональным видам хлеба. Результаты ответов респондентов на данный вопрос подтверждают заинтересованность и готовность большинства потребителей в приобретении функциональных хлебных изделий.

УРОВЕНЬ ИНФОРМИРОВАННОСТИ

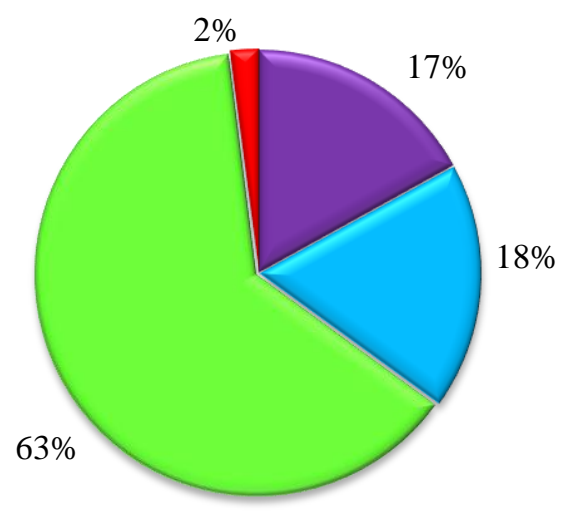

$$
\begin{aligned}
& \text { 口 отсутствие } \\
& \text { информированности } \\
& \text { ■изкий уровень } \\
& \text { информированности } \\
& \text { высокий + средний уровень } \\
& \text { информированности } \\
& \text { в отсутствие } \\
& \text { информированности и } \\
& \text { нежелание что-либо узнать }
\end{aligned}
$$

Рисунок 1. Информированность населения Красноярска о функциональных хлебных изделиях

Figure 1. Awareness of the population of Krasnoyarsk about functional bread products

Самооценка здоровья населением Красноярска представлена на рис. 2. Оценивая свое здоровье, менее половины (42\%) респондентов ответили, что удовлетворены, считая себя в целом здоровыми (32\%) или совершенно здоровыми $(10 \%)$. На долю неудовлетворенных состоянием своего здоровья пришлось 56\% респондентов, из которых 45\% опрашиваемых имеют хронические заболевания, $11 \%$ - в холодное время года заболевают ОРВИ, ОРЗ. Затруднение при ответе на этот вопрос испытывали 2\% участников опроса.

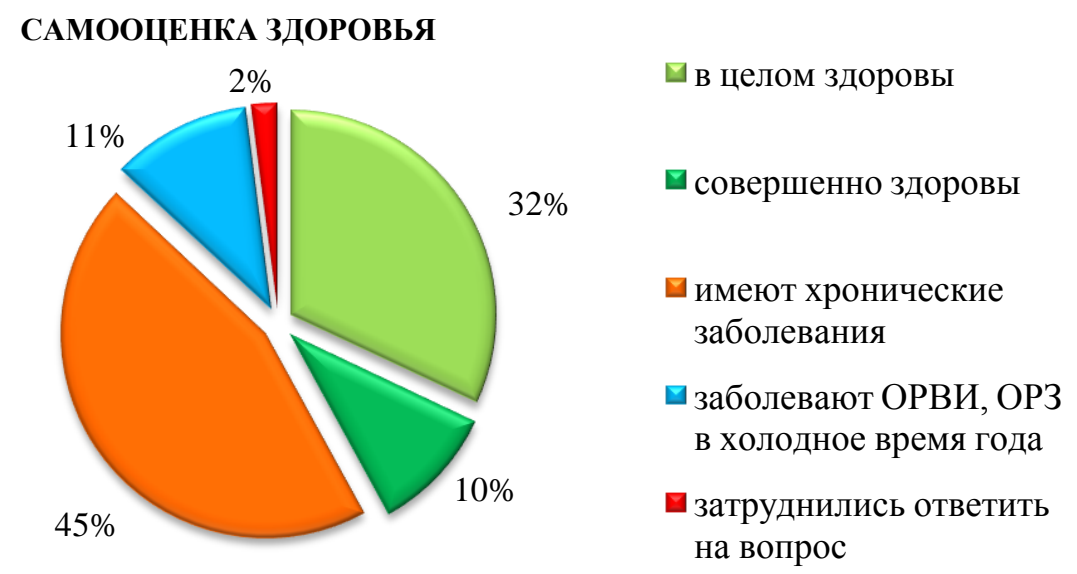

Рисунок 2. Самооценка здоровья населением Красноярска Figure 2. Self-assessment of health by the population of Krasnoyarsk 
В числе факторов неблагоприятного влияния на здоровье более половины респондентов указали экологическое неблагополучие, эмоционально-физиологические стрессы, связанные с современным ритмом жизни (51\%), треть респондентов - неправильное / нездоровое питание и наследственность (31\%), напряженные условия работы / учебы отметили $17 \%$ опрашиваемых и $1 \%$ - затруднялись с ответом.

При выявлении предпочтений к видам хлеба мнения среди анкетируемых разделились (рис. 3). Причем большинство опрашиваемых проявляют определенный интерес к оригинальным (27\%) и полезным (54\%) видам хлебной продукции, вариант «разные из вышеперечисленных» выбрали $12 \%$ респондентов, интерес к традиционным видам хлеба проявили 6\% опрашиваемых. Лишь 1\% опрашиваемых предложили свой вариант, отобразив его в установленном элементе анкеты «Ваш вариант». В обобщенном виде ответы выглядят следующим образом: «хлеб не употребляю», «вкусный и красивый», «не черствеющий», «приемлемый по стоимости», «низкокалорийный».

Анализ данных показал довольно высокий интерес потребителей к полезным и оригинальным видам хлебной продукции, это подтверждает гипотезу необходимости разработки функциональной продукции в разрезе данной продовольственной группы.

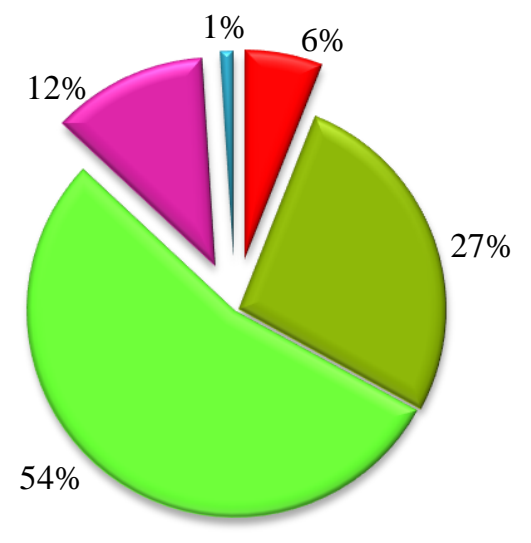

\author{
ВИДЫ ХЛЕБА \\ 曰 традиционные \\ ๑ оригинальные \\ полезные \\ 口азные из \\ вышеперечисленных \\ $\square$ Ваш вариант
}

Рисунок 3. Предпочтения населения Красноярска к видам хлеба Figure 3. Preferences to types of bread of the population of Krasnoyarsk

При анализе ответов на вопросы, связанные с количеством потребления в рационе хлеба и хлебных изделий, выявлено, что в основном женщины в возрасте от 20 до 60 лет ограничивают его употребление, называя самые разнообразные причины, однако полностью эти продукты никто не исключает из собственного рациона питания.

В ходе опроса респондентов по выбору предпочитаемой массы хлебного изделия мнения разделились и варьировали в широких пределах: от вариантов 200-300 г (мелкоштучный хлеб) до 400-1000 г (ординарная масса). Это подтверждает целесообразность получения новых видов хлеба в ассортименте с актуально широким диапазоном массы, что позволяет оптимально реализовать цели питания потребителя.

В качестве вариантов обогащения и придания функциональных свойств хлебным изделиям $72 \%$ респондентов предпочли использование растительного сырья (рис. 4), при этом некоторые считают возможным дополнить состав хлебных изделий комплексом полезных ингредиентов на основе синергии сочетаний «растительное сырье + витамины», «растительное сырье + микроэлементы».

Мнение 96\% участников опроса подтверждает пользу ягод клюквы, брусники, черники, голубики для организма человека. Вместе с тем большинство респондентов (89\%) ответили, что не встречали в торговой сети хлеб с ягодами клюквы, брусники, черники, голубики; встречали в продаже хлеб с клюквой 10\% опрашиваемых, у 1\% респондентов ответ на этот вопрос вызвал затруднение. 


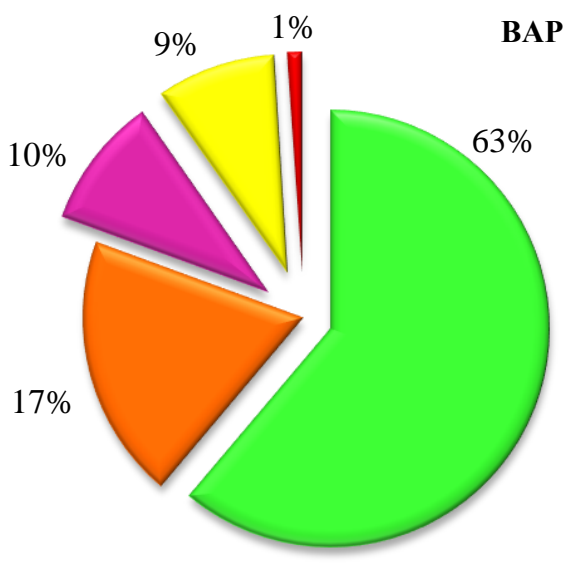

ВАРИАНТЫ ОБОГАЩЕНИЯ ХЛЕБА

\author{
$\square$ растительное сырье \\ В витаминный комплекс \\ 甲 минеральный комплекс \\ $\square$ разные из \\ вышеперечисленных \\ 口 Ваш вариант
}

Рисунок 4. Предпочтения населения Красноярска к вариантам обогащения хлеба Figure 4. Preferences of the population of Krasnoyarsk to options of bread enrichment

Полученные в ходе анкетного опроса данные дали возможность отметить определенный потребительский интерес к хлебной продукции $\mathrm{c}$ использованием растительного сырья, а также с введением дополнительно витаминных и минеральных премиксов, что обеспечит спрос потребителей к функциональным видам хлеба.

Также на основании предпочтений потребителей и отсутствия на потребительском рынке хлеба с добавками из ягод семейства вересковых, рассмотрена возможность выбора плодов семейства вересковых в качестве растительной основы для обогащения и придания функциональных свойств хлебным изделиям.

В современных условиях, в мире индустриальных технологий и технократических подходов, велики факторы риска попадания токсичных контаминантов в растительное сырье. Была изучена токсикологическая безопасность, включая содержание тяжелых металлов, плодов клюквы, брусники, черники, голубики, заготовленных в Шушенском, Енисейском и Канском районах Красноярского края, являющихся перспективными ингредиентами для обогащения функциональных видов хлеба. Показатели токсикологической безопасности представлены в табл. 1.

Таблица 1. Показатели токсикологической безопасности свежих ягод семейства Ericaceae, заготовленных в Шушенском, Енисейском и Канском районах Красноярского края

Table 1. Indicators of toxicological safety of fresh berries of the family Ericaceae, harvested in Shushenskiy, the Yeniseysky and Kansky districts of Krasnoyarsk Region

\begin{tabular}{|c|c|c|c|c|c|}
\hline \multirow{2}{*}{$\begin{array}{c}\text { Показатели, единицы } \\
\text { измерения }\end{array}$} & \multicolumn{4}{|c|}{ Результаты эксперимента } & Гигиенический \\
\cline { 1 - 6 } & $\begin{array}{c}\text { Vaccinium } \\
\text { oxycoccos L. }\end{array}$ & $\begin{array}{c}\text { Vaccinium } \\
\text { vitis-idaea L. }\end{array}$ & $\begin{array}{c}\text { Vaccinium } \\
\text { myrtillus L. }\end{array}$ & $\begin{array}{c}\text { Vaccinium } \\
\text { uliginosum L. }\end{array}$ & $\begin{array}{c}\text { норматив ПДК } \\
\text { по данным[49]) }\end{array}$ \\
\hline Кадмий $(\mathrm{Cd})$, мг/кг & $<0,0002$ & $<0,0002$ & $<0,0002$ & $<0,0002$ & 0,030 \\
\hline Свинец $(\mathrm{Pb})$, мГ/кГ & $<0,02$ & $<0,02$ & $<0,02$ & $<0,02$ & 0,40 \\
\hline Ртуть $(\mathrm{Hg})$, мг/кГ & $<0,0002$ & $<0,0002$ & $<0,0002$ & $<0,0002$ & 0,020 \\
\hline Мышьяк $(\mathrm{As})$, мГ/кГ & $<0,002$ & $<0,002$ & $<0,002$ & $<0,002$ & 0,2 \\
\hline Цезий $(\mathrm{Cs})-137$, Бк/кГ & $<1,0$ & $<1,0$ & $<1,0$ & $<1,0$ & 160 \\
\hline Стронций $(\mathrm{Sr})-90$, Бк/кг & $<2,0$ & $<2,0$ & $<2,0$ & $<2,0$ & $60^{*}$ \\
\hline
\end{tabular}

*номенклатура показателей расширена, гигиенический норматив ПДК взят согласно данным СанПиН 2.3.2.1078-01 [50].

Ягоды семейства вересковых - сезонное сырье, их использование в свежем виде ограничивается фактором времени, поэтому возникает вопрос поиска вариантов их сохранения и круглогодичного использования как функциональных ингредиентов $[8,24]$. В 
качестве форм переработки указанного растительного сырья для обогащения функциональных видов хлеба круглогодично, были выбраны варианты [8, 14, 20, 24]:

- 1 вариант - насыщение ягод сиропом на основе бактерицидного лекарственнотехнического сырья, входящего в перечень добавок, разрешенных для введения в функциональные продукты [8], с нейтральным или приятным вкусом;

- 2 вариант - получение порошков из сушеных ягод с размером частиц < 1 мм;

- 3 вариант (ресурсосберегающий, безотходный) - получение порошков из сушеных выжимок ягод (отходов сокового производства) с размером частиц $<1$ мм [8].

Поскольку в процессе сушки из плодов удаляется влага, возрастает содержание сухих веществ, и соответственно концентрация всех элементов, включая тяжелые металлы, это вызывает необходимость исследовать показатели безопасности порошков из сушеных ягод на соответствие требованиям ТР ТС 021/2011 и СанПиН 2.3.2.1078-01 [49, 50]. Результаты представлены в табл. 2.

Таблица 2. Показатели токсикологической безопасности порошков из сушеных ягод семейства Ericaceae, собранных в Шушенском, Енисейском и Канском районах

Красноярского края

Table 2. Indicators of toxicological safety of powders from dried berries of the family Ericaceae, harvested in the Shushensky, Yeniseysky and Kansky districts of Krasnoyarsk Region

\begin{tabular}{|c|c|c|c|c|c|}
\hline \multirow{3}{*}{$\begin{array}{c}\text { Показатели, единицы } \\
\text { измерения }\end{array}$} & \multirow{2}{*}{\multicolumn{4}{|c|}{$\begin{array}{l}\text { Результаты эксперимента } \\
\text { Порошки из сушеных ягод }\end{array}$}} & \multirow{3}{*}{$\begin{array}{l}\text { Гигиенический } \\
\text { норматив ПДК } \\
\text { (по данным[49]) }\end{array}$} \\
\hline & & & & & \\
\hline & $\begin{array}{c}\text { Vaccinium } \\
\text { oxycoccos } L \text {. }\end{array}$ & \begin{tabular}{|c|} 
Vaccinium \\
vitis-idaea $L$.
\end{tabular} & $\begin{array}{l}\text { Vaccinium } \\
\text { myrtillus L. }\end{array}$ & $\begin{array}{c}\text { Vaccinium } \\
\text { uliginosum } L .\end{array}$ & \\
\hline Кадмий (Cd), мг/кг & $<0,002$ & $<0,002$ & $<0,002$ & $<0,002$ & $0,030 / 0,219 *$ \\
\hline Свинец $(\mathrm{Pb})$, мг/кг & & $<0$ & $<0,2$ & & $0,40 /$ \\
\hline Ртуть $(\mathrm{Hg})$, мг/кг & $<0,002$ & $<0,002$ & $<0,002$ & $<0,002$ & $0,020 / 0,146^{*}$ \\
\hline Мышьяк (As), мг/кг & & $<0,02$ & $<0,02$ & & $0,2 / 1,461^{*}$ \\
\hline Цезий (Cs)-137, Бк/кг & $<12,0$ & $<12,0$ & $<12,0$ & $<12,0$ & 800 \\
\hline Стронций (Sr)-90, Бк/кг & $<24,0$ & $<24,0$ & $<24,0$ & $<24,0$ & $300 * *$ \\
\hline
\end{tabular}

* гигиенический норматив ПДК в порошках из сушеных ягод определен и учтен с пересчетом в соответствии с содержанием сухих веществ в исходном сырье (свежих ягодах) и в конечном продукте (ягодных порошках 95,00\%) согласно данным [49].

** номенклатура показателей расширена, гигиенический норматив ПДК взят согласно данным СанПиН 2.3.2.1078-01 [50].

По данным, представленным в табл. 1 и 2, видно, что все показатели токсикологической безопасности исследуемых образцов, как свежих ягод семейства вересковых, так и порошков из сушеных ягод этого семейства, существенно ниже гигиенических нормативов ТР ТС 021/2011 и СанПиН 2.3.2.1078-01 [49, 50], что подтверждает возможность введения их в состав функциональных видов хлеба. Исходя из этого, основываясь на методе комбинаторного анализа $[47,48]$, был выполнен предварительный прогноз видового разнообразия нового функционального хлеба массового ассортимента с добавками из ягод семейства вересковых.

Как показали результаты комбинаторного анализа, наличие даже небольшого ассортимента растительного сырья позволит значительно расширить видовой ассортимент хлеба и хлебных изделий и тем самым разнообразить рацион питания. К примеру, наличие четырех видов сухого растительного сырья, в частности четырех плодово-ягодных ингредиентов (порошки из клюквы, брусники, черники, голубики) даст возможность составить более десяти видов хлеба, рассматривая сочетания без повторений, и около семидесяти, если учитывать повторение ингредиента при фиксированной массе растительного наполнителя. Расчеты проводили по формуле [48]. Число вариантов сочетаний из $\mathrm{n}$ элементов по $\mathrm{m}$ элементов равно: 
$C_{n}^{m}=\frac{n !}{(n-m) ! \cdot m !}$

где $\mathrm{m} \geq 0, \mathrm{n} \geq \mathrm{m}$.

Число возможных сочетаний из 4-х элементов - порошков из растительного сырья (клюквы, брусники, черники, голубики) равно:

$N_{1}=C_{4}^{1}+C_{4}^{2}+C_{4}^{3}+C_{4}^{4}=15$

При наличии 4-х элементов можно составить в целом 15 непустых сочетаний.

Если имеется четыре различных растительных ингредиента в достаточном количестве, можно составить из этих четырех элементов сочетания с повторениями по формуле вычисления сочетаний с повторениями [48]:

$\mathrm{C}_{\mathrm{n}(\text { повm })}^{\mathrm{m}}=C_{n+m-1}^{m}=\frac{(n+m-1) !}{m !(n-1) !}$,

где $n \geq m$ (так же возможен вариант при $\mathrm{m} \geq \mathrm{n}$ ).

Если задано 4 различных элементов и требуется составить сочетания с повторениями из этих четырех элементов, то число сочетаний с повторениями из 4 элементов равно:

$N_{2}=C_{4+1-1}^{1}+C_{4+2-1}^{2}+C_{4+3-1}^{3}+C_{4+4-1}^{4}=69$.

При наличии 4 элементов можно составить в целом 69 непустых сочетаний с повторениями. Комбинации различных наполнителей (добавок) и их соотношений, как показывают математические расчеты, позволяют получать множество многовариантных фитокомпозиций для создания новых видов функционального хлеба.

Сумма полученных в работе данных послужила основой для формирования ассортиментной концепции функционального хлеба массового ассортимента.

Ассортиментная концепция видового разнообразия функционального хлеба массового ассортимента актуального качества для здорового питания сформирована на основании результатов социологического опроса, анализа химического состав, исследования безопасности дикорастущих ягод семейства вересковых и порошков из них, подбора форм введения растительного сырья и данных комбинаторного анализа видовых вариантов нового хлеба. При формировании концепции, также учтен факт отсутствия на потребительском рынке хлеба, изделий с добавками из ягод семейства вересковых. Для большей наглядности концепция представлена в виде схемы-матрицы (рис. 5).

Выводы и дискуссионные вопросы.

1. Результаты социологического опроса рассмотрены как вариант распределения предпочтений потенциальных потребителей, показывающих заинтересованность, потребность населения по отношению к тем или иным видам продуктов потребления, их потребительским свойствам, задавая возможные направления в формировании актуального качества объекта исследования, в данном случае функционального хлеба. Поскольку данные опроса не являются безусловным фактором, для создания оптимального варианта пищевого продукта с актуальным уровнем качества требуются дополнительные экспериментальные исследования. Вполне целесообразно данные результата опроса использовать на этапе «идея - концепция - композиционный профиль - принципиальный образ».

2. Полученные данные социологического опроса в большей или меньшей степени подтверждают потребительский спрос на функциональные виды хлеба.

3. Участники исследования показали уверенность в необходимости введения в состав хлеба с целью его обогащения биоэлементами и придания функциональных свойств, при этом допуская возможность дополнительного усиления, добавления пользы хлебным изделиям в результате синергии сочетаний «растительная добавка + витамины», «растительная добавка + микроэлементы», «растительная добавка + витамины и микроэлементы». Так же потребитель хорошо информирован о пользе ягод семейства вересковых и важным качеством для хлеба считает эффект античерствения (долго не черствеющий хлеб).

4. Проведен анализ имеющихся данных о пищевой ценности и потребительских свойствах ягод семейства вересковых (клюквы, брусники, черники, голубики), а также оценка возможного места сбора сырья. 


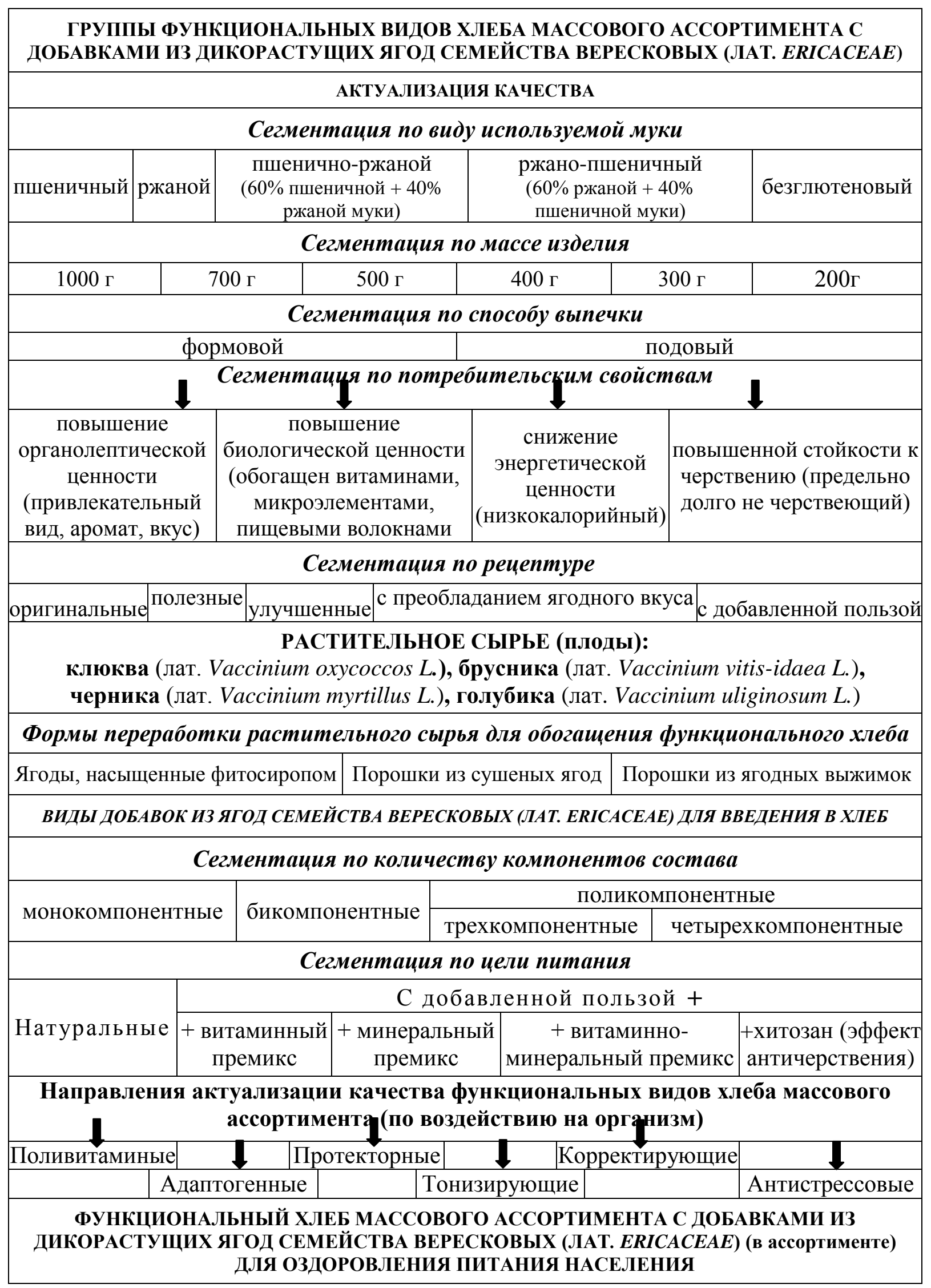

Рисунок 5. Ассортиментная концепция видового разнообразия функционального хлеба массового ассортимента актуального качества для оздоровления питания населения Figure 5. Assortment concept of species diversity of functional bread of mass assortment of contemporary quality for health improving the nutrition of the population 
5. Определены оптимальные формы добавок из ягод семейства вересковых как функциональных ингредиентов хлебных изделий, дающие возможность круглогодичного использования растительных ингредиентов с сохранением биологически активных веществ, а также увеличения интенсивности промышленного использования.

6. Исследованиями показателей токсикологической безопасности свежих ягод и порошков из сушеных ягод семейства вересковых подтверждена их безопасность и возможность их введения в состав функциональных видов хлеба.

7. Осуществлен предварительный прогноз видового разнообразия нового функционального хлеба массового ассортимента с добавками из ягод семейства вересковых с применением метода комбинаторного анализа, подтвердивший многовариантность и широкое развитие ассортимента новых видов хлеба.

8. На основании результатов исследований определены перспективные направления актуализации качества функциональных видов хлеба массового ассортимента, сформирована ассортиментная концепция видового разнообразия функционального хлеба массового ассортимента актуального качества для оздоровления питания.

\section{Библиографический список}

1. Уголев, А.М. Теория адекватного питания и трофология [Текст] / А.М. Уголев. М.: Концептуал, 2018. - 288 с.

2. Министерство здравоохранения Российской Федерации [Электронный ресурс]. URL : http://www.rosminzdrav.ru.

3. Bigliardi, B. Innovation trends in the food industry: The case of functional foods [Text] / B. Bigliardi, F. Galati // Trends in Food Science \& Technology. - 2013. - Vol. 31, № 2. - Pp. $118-129$.

4. Galland, L. Functional Foods: Health Effects and Clinical Applications [Text] // Encyclopedia of Human Nutrition (Third Edition) / L. Galland. - New York : Applied Nutrition Inc., 2013. - Pp. 366-371.

5. Lucas, J. EU-funded research in functional foods. [Text] / J.Lucas // Britich J. Nutrition. - 2002. - V. 88, Suppl. 2. - Pp. 131-132.

6. Milner, J.A. Functional foods and health: a US perspective [Text] / J.A. Milner // British J. Nutrition. - 2002. - Vol. 88, Suppl. 2. - Pp. 151-158.

7. Кайрос, Н. Пробиотики и ферменты. Суперфуд XXI века [Текст] / Н/ Кайрос. СПб. : Питер, 2013. - 120 с.

8. Теоретические и практические аспекты формирования качества продуктов переработки растительного сырья Сибирского региона : монография [Текст] / И.Н. Пушмина; Краснояр. гос. торг.-экон. ин-т. - Красноярск, 2010. - 226 с.

9. О Стратегии национальной безопасности Российской Федерации до 2020 года : Указ Президента Российской Федерации от 12 мая 2009 № 537 [Текст] // Собрание законодательства Российской Федерации от 2009 г., № 20, ст. 2444. - Москва, 2009.

10. Основы государственной политики Российской Федерации в области здорового питания на период до 2020 года: Распоряжение Правительства РФ от 25 октября 2010 г. № 1873-p [Электронный ресурc]. URL : http://www.rg.ru/2010/11/03/pravila-dok.html.

11. Стратегия развития пищевой и перерабатывающей промышленности Российской Федерации на период до 2020 года [Текст]. - Утверждена распоряжением Правительства РФ от 17 апреля 2012 г. № 559-р.

12. Прогноз развития научно-технологического развития Российской Федерации до 2030 года [Текст]. - Москва, 2013. - 72 с.

13. Binnur, K. \& Serap, K. Consumers' Attitude towards Food Additives [Text] / K. Binnur, K. Serap // American Journal of Food Science and Nutrition Research.-2015.-2(2). - Pp.21-25.

14. BO3. Безопасность продуктов питания [Электронный ресурс]. - URL: http://www.whogis.com/mediacentre/factsheets/fs399/ru/. 
15. Neveen, H.M. Toxic effects of the synthetic food dye brilliant blue on liver, kidney and testes functions in rats [Text] / H.M. Neveen // Journal of the Egyptian Society of Toxicology. 2006. - № 34. - Pp. 77-84.

16. Biliaderis, C.G. Functional Food Carbohydrates [Text] / C.G. Biliaderis, M.S. Jzydorczyk. - CRC Press, 2003. - 577 p.

17. Arai, S. Global view on functional foods: Asian perspectives [Text] / S. Arai // British J / Nutrition. - 2002. - Vol. 88, Supple 2. - Pp. 139-143.

18. Roberfroid, M.B. Global view on functional foods: European perspectives [Text] / M.B. Roberfroid // British J. Nutrition. - 2002. - Vol. 88, Suppl.2. - Pp. 133-138.

19. Verschuren, P.M. Functional Foods: Scientific and Global Perspecnives (Summary Report) [Text] / P.M. Verschuren //Britich J. Nutrition. - 2002. - Vol. 88, Suppl. 2. - Pp.125-130.

20. Grynkiewicz, G. Phytochemicals Between Nutrition and Medicine [Text] / G. Grynkiewicz // Acta Scientific Nutrition Health. - 2020. - No 4.1, 4. - Pp. 24-29.

21. Shi, J. Functional Food Ingredients and Nutraceuticals: Processing Technologies [Text] / J. Shi. - CRC Press, 2002. - 428 p.

22. Schmidl, M.K. Essentials of Functional Foods [Text] / M.K. Schmidl, T.P. Labuza. Springer - London. 2004. - 406 p.

23. Джабоева, А.С. Дикорастущие плоды - перспективное сырье для извлечения биологически активных веществ [Текст] / А.С. Джабоева, М.Ю. Тамова, А.С. Кабалоева, 3.С. Думанишева, Л.Г. Шаова, Д.Р. Соваева // Известия высших учебных заведений. Пищевая технология. - 2007. - № 5-6. - С. 21-23.

24. Пушмина, В.В. Обоснование выбора растительного сырья и форм его переработки для обогащения пищевых продуктов [Текст] / В.В. Пушмина, И.Н. Пушмина, Г.Г. Первышина, Л.М. Захарова // Известия ДВФУ. Экономика и управление.- 2017. - №3. - С. 137-149.

25. Будинцева, А.JI. Дикорастущие полезные растения России [Текст] / А.JI. Будинцева, Е.Е. Лесковская. - СПб, 2000. - 663 с.

26. Пушмина, И.Н. Формирование ассортиментной концепции спортивных фитонапитков [Текст] / И.Н. Пушмина, М.Д. Кудрявцев, В.В. Пушмина и др. // Человек. Спорт. Медицина. - 2018. - Т.18, №3. - С. 77-89.

27. Рабинович, А.М. Лекарственные растения России [Текст] / А.М. Рабинович. Москва : ОЛМА-ПРЕСС, 2001. - 319 с.

28. Курлович, Т.В. Брусника, голубика, клюква, черника [Текст] / Т.В. Курлович. Москва : Издательский дом МСП, 2005. - 128 с.

29. Характеристика природных ресурсов Красноярского края [Электроный ресурс]. URL : http://knowledge.allbest.ru/geography/2c0a65635b3ac68b4d53a89521206c37_0.html.

30. Borowska I. Antioxidant Activity of Berry Fruits and Beverages [Text] / I. Borowska // Polish Journal of Natural Sciences. - 2003. - № 4. - Pp. 521-528.

31. Kartimo, H. Characterization of phenolic compounds from lingonberry (Vaccin-ium vitis-idaea) [Text] / H. Kartimo, S. Mattila, A. Tolonen // J. Agric. Food Chem. 2006. - № 54, Pp. 9834-9842.

32. Лютикова, М.Н. Химический состав и практическое применение ягод брусники и клюквы [Текст] / М.Н. Лютикова, Э.Х. Ботиров // Химия растительного сырья . - 2015. - № 2. - C. 5-27.

33. He, J. Anthocyanins: Natural Colorants with Health-Promoting [Text] / J. He, M. Giusti // Properties Annual Review of Food Science and Technology. - 2010. - № 1 (1). - P. 163-187. doi:10.1146/annurev.food.080708.100754.

34. Государственная Фармакопея СССР. - 11-е изд. - М. : Медицина, 1990. - Вып. 2. $-400 \mathrm{c}$.

35. Министерство экологии и рационального природопользования Красноярского края [Сайт : Состояние окружающей среды] [Электронный ресурc]. - URL : http://www.mpr.krskstate.ru/envir. 
36. Краевая ведомственная информационно-аналитическая система данных о состоянии окружающей среды Красноярского края [Электронный ресурс] / Администрация г. Красноярска. - URL : https://krasecology.ru/.

37. Государственный доклад «О состоянии и охране окружающей среды в Красноярском крае в 2019 году» [Текст]. - Красноярск, 2020. - 310 с.

38. Лотош, В.Е. Экология природопользования [Текст] / В.Е. Лотош. - Екатеринбург : Полиграфист, 2001. - 540 с.

39. Siro, I. Functional food. Product development, marketing and consumer acceptance - A review [Text] / I. Siro, E. 3. Kapolna, B. Kapolna, A. Lugasi // Appetite. - 2008. - Vol. 51, № 3. Pp. 456-467.

40. Lusk, J.L. Distinguishing Beliefs from Preferences in Food Choice [Text] / J.L. Lusk, T.C. Schroeder, G.T. Tonsor // European Review of Agricultural Economics. - 2014. - No 41 (4). Pp. 627-655.

41. Casey, M.A. Focus Group Interviewing. H.J.H. MacFie and D.M.H. Thomson (Eds.) Measurement of Food Preferences [Text] / M.A. Casey, R.A. Krueger. - London: Blackie Academic and Professional, 1994. - Pp. 77-96.

42. ISO 9000: 2015 Quality management systems. Fundamentals and vocabulary, IDT [Electronic source]. - URL Access mode: https://www.iso.org/standard/45481.html.

43. Распределение численности населения Красноярского края по полу и отдельным возрастным группам на начало года [Электронный ресурс]: Официальная статистика Территориального органа Федеральной службы государственной статистики по Красноярскому краю. - $\quad$ Красноярск, 2016. http://krasstat.gks.ru/wps/wcm/connect/rosstat_ts/krasstat/resources.

44. Федеральная служба государственной статистики [Электронный ресурс]. - URL : http://gks.ru.

45. Государственная фармакопея СССР. Вып. 1. Т. І ГФХІ [Текст] / под ред. Ю.Г. Бобкова и др. - М.: Медицина, 1987. - 333 с.

46. Руководство по методам анализа качества и безопасности пищевых продуктов [Текст] / под ред. И.М. Скурихина, В.А. Тутельяна. - М.: Брандес, Медицина, 1998. - 340 с.

47. Гнеденко, Б.В. Курс теории вероятностей: учебник [Текст] / Б.В.Гнеденко. - Изд. 6-е, прераб. и доп. - М. : Наука. Гл. ред. физ.-мат. лит., 1988. - 448 с.

48. Виленкин, Н.Я. Комбинаторика [Текст] / Н.Я. Виленкин, А.Н. Виленкин, П.А. Виленкин. - М.: ФИМА, МЦНМО, 2006. - 400 с.

49. Технический регламент Таможенного союза «О безопасности пищевой продукции» (ТР ТС 021/2011) [Электронный ресурс]: решение Коллегии Евразийской экономической комиссии от 09.12.2011 № 880. // Справочная правовая система «КонсультантПлюс». - URL : http://www.consultant.ru.

50. Санитарно-эпидемиологические правила и нормативы «Гигиенические требования безопасности и пищевой ценности пищевых продуктов» (СанПиН 2.3.2.10782001) [Электронный ресурс] : утверждены Главным государственным санитарным врачом РФ 06-11-2001. - Введены в действие с 01-09-2002. // Справочная правовая система «КонсультантПлюс». - URL : http://www.consultant.ru.

\section{References}

1. Ugolev, A.M. (2018). The theory of adequate nutrition \& trophology. Moscow. Conceptual. 288 p.

2. Ministry of Health of the Russian Federation [Electronic resource]. URL : http://www.rosminzdrav.ru.

3. Bigliardi, B. \& Galati, F. (2013). Innovation trends in the food industry: The case of functional foods. Trends in Food Science \& Technology. Vol. 31, No. 2. Pp. 118-129.

4. Galland, L. (2013). Functional Foods: Health Effects \& Clinical Applications. In: Encyclopedia of Human Nutrition (3-d Edition). New York. Applied Nutrition Inc. Pp. 366-371. 
5. Lucas, J. (2002). EU-funded research in functional foods. Britich J. Nutrition. Vol. 88, Suppl. 2. Pp. 131-132.

6. Milner, J.A. (2002). Functional foods \& health: a US perspective. British J. Nutrition. Vol. 88, Suppl. 2. Pp. 151-158.

7. Kairos, N. (2013). Probiotics \& enzymes. Superfood of the XXI century. St. Petersburg. Peter. $120 \mathrm{p}$.

8. Theoretical \& practical aspects of formation of quality of products of processing of vegetable raw materials of the Siberian region (2010). Krasnoyarsk State Trade \& Economic Institute. $226 \mathrm{p}$.

9. On the National Security Strategy of the Russian Federation until 2020 : Decree of the President of the Russian Federation No. 537 of May 12, 2009. Collection of Legislation of the Russian Federation of 2009, No. 20, Article 2444. Moscow.

10. Fundamentals of the State policy of the Russian Federation in the field of healthy nutrition for the period up to 2020: Order of the Government of the Russian Federation No. 1873-r of October 25, 2010 [Electronic resource]. URL : http://www.rg.ru/2010/11/03/pravila-dok.html.

11. Strategy for the development of the food \& processing industry of the Russian Federation for the period up to 2020. Approved by Order of the Government of the Russian Federation No. 559-r of April 17, 2012.

12. Forecast of scientific \& technological development of the Russian Federation until 2030. Moscow. 2013. 72 p.

13. Binnur, K. \& Serap, K. (2015). Consumers' Attitude towards Food Additives. American Journal of Food Science \& Nutrition Research. No 2(2). Pp.21-25.

14. WHO Food safety [Electronic resource]. URL http://www.whogis.com/mediacentre/factsheets/fs399/ru/.

15. Neveen, H.M. (2006). Toxic effects of the synthetic food dye brilliant blue on liver, kidney \& testes functions in rats. Journal of the Egyptian Society of Toxicology. No. 34. Pp. 77-84.

16. Biliaderis, C.G. \& Jzydorczyk, M.S. (2003). Functional Food Carbohydrates. CRC Press. 577 p.

17. Arai, S. (2002). Global view on functional foods: Asian perspectives. British J. Nutrition. Vol. 88, Supple 2. Pp. 139-143.

18. Roberfroid, M.B. (2002). Global view on functional foods: European perspectives. British J. Nutrition. Vol. 88, Suppl.2. Pp. 133-138.

19. Verschuren, P.M. (2002). Functional Foods: Scientific \& Global Perspecnives (Summary Report). Britich J. Nutrition. Vol. 88, Suppl. 2. Pp.125-130.

20. Grynkiewicz, G. (2020). Phytochemicals Between Nutrition \& Medicine. Acta Scientific Nutrition Health. No 4.1, 4. Pp. 24-29.

21. Shi, J. (2002). Functional Food Ingredients \& Nutraceuticals: Processing Technologies. J. Shi. CRC Press. 428 p.

22. Schmidl, M.K. (2004). Essentials of Functional Foods / M.K. Schmidl, T.P. Labuza. Springer, London. 406 p.

23. Gabaeva, A.S., Tomova, M.Y., Kabaloev, A.S., Dominicia, Z.S., Shaova, L.G. \& Avaeva, D.R. (2007). Wild fruits is a promising raw material for the extraction of biologically active substances. News of higher educational institutions. Food technology. No. 5-6. Pp. 21-23.

24. Pushmina, V.V., Pushmina, I.N., Pervyshina, G.G. \& Zakharova, L.M. (2017). Justification of the choice of plant raw materials \& forms of its processing for the enrichment of food products. News of the FEFU. Economics \& management. No. 3. Pp. 137-149.

25. Budintseva, A. L. \& Leskovskaia, E. E. (2000). Wild useful plants of Russia. St. Petersburg. 663 p.

26. Pushmina, I. N., Kudryavtsev, M. D., Pushmina, V. V. et al. (2018). Formation of the assortment concept of sports phytonapitals. Man. Sports. Medicine. Vol. 18, No. 3. Pp. 77-89.

27. Rabinovich, A.M. (2001). Medicinal plants of Russia. Moscow. OLMA-PRESS. 319 p. 
28. Kurlovich, T. V. (2005). Lingonberries, blueberries, cranberries, blueberries. Moscow. MSP Publishing House. 128 p.

29. Characteristics of natural resources of the Krasnoyarsk Territory [Electron / resource]. URL: http://knowledge.allbest.ru/geography/2c0a65635b3ac68b4d53a89521206c37_0.html.

30. Borowska I. (2003). Antioxidant Activity of Berry Fruits \& Beverages. Polish Journal of Natural Sciences. No. 4. Pp. 521-528.

31. Kartimo, H., Mattila, S. \& Tolonen A. (2006). Characterization of phenolic compounds from lingonberry (Vaccin-ium vitis-idaea. J. Agric. Food Chem. No. 54. Pp. 9834-9842.

32. Lyutikova, M.N. \& Botirov E.H. (2015). Chemical composition \& practical application of cranberry \& cranberry berries. Chemistry of plant raw materials. No. 2. Pp. 5-27.

33. He, J. \& Giusti, M. (2010). Anthocyanins: Natural Colorants with Health-Promoting. Properties Annual Review of Food Science \& Technology. No. 1(1). Pp. 163-187. doi:10.1146/annurev.food.080708.100754.

34. State Pharmacopoeia of the USSR (1990). 11th ed. Moscow. Meditsina. 400 p.

35. Ministry of Ecology \& Rational Nature Management of the Krasnoyarsk Territory [Website: State of the Environment] [Electronic resource]. URL : http://www.mpr.krskstate.ru/envir.

36. Regional departmental information \& analytical system of data on the state of the environment of the Krasnoyarsk Territory [Electronic resource]. Administration of Krasnoyarsk. URL : https://krasecology.ru/.

37. State Report "On the state \& protection of the environment in the Krasnoyarsk Territory in 2019". Krasnoyarsk. 2020. 310 p.

38. Lotosh, V.E., (2001). The Ecology of natural resources. Yekaterinburg. Polygraphist. 540 p.

39. Siro, I., Kapolna, E., Kapolna, B., Lugasi, A. (2008). Functional food. Product development, marketing \& consumer acceptance - A review. Appetite. Vol. 51, No. 3. Pp. 456-467.

40. Lusk, J.L., Schroeder, T.C., Tonsor, G.T. (2014). Distinguishing Beliefs from Preferences in Food Choice. European Review of Agricultural Economics. No 41 (4). Pp. 627-655.

41. Casey, M.A., Krueger, R.A. (1994). Focus Group Interviewing. H.J.H. MacFie \& D.M.H. Thomson (Eds.). Measurement of Food Preferences. London. Blackie Academic \& Professional. Pp. 77-96.

42. ISO 9000: 2015 Quality management systems. Fundamentals \& vocabulary, IDT [Electronic source]. - URL Access mode: https://www.iso.org/standard/45481.html.

43. Distribution of the population of the Krasnoyarsk Territory by gender \& individual age groups at the beginning of the year [Electronic resource]: Official statistics of the Territorial Body of the Federal State Statistics Service for the Krasnoyarsk Territory. Krasnoyarsk. 2016. URL: http://krasstat.gks.ru/wps/wcm/connect/rosstat_ts/krasstat/resources.

44. Federal State Statistics Service [Electronic resource]. URL : http://gks.ru.

45. State Pharmacopoeia of the USSR (1987). Issue 1. So I GFH. Ed. by Yu.G. Bobkov et al. Moscow. Meditsina. 333 p.

46. Guide to methods of analyzing the quality \& safety of food products (1998). Ed. by I.M. Skurikhin, V. A. Tutelyan. Moscow. Brandes, Meditsina. 340 p.

47. Gnedenko, B.V. (1988). Course of probability theory. Moscow. Nauka. 448 p.

48. Vilenkin, N.Ya., Vilenkin, A.N. \& Vilenkin P.A. (2006). Combinatorics. Moscow. FIMA, ICNMO. 400 p.

49. Technical regulations of the Customs Union "On food safety" (TP CU 021/2011) [Electronic resource]: decision of the Board of the Eurasian Economic Commission of 09.12.2011 No. 880. Reference legal system "ConsultantPlus". URL : http://www.consultant.ru.

50. Sanitary \& epidemiological rules \& regulations "Hygienic requirements for the safety \& nutritional value of food products" (SanPiN 2.3.2.1078-2001) [Electronic resource] : approved by the Chief State Sanitary Doctor of the Russian Federation 06-11-2001. Put into effect from 01-092002. Reference legal system "ConsultantPlus". URL : http://www.consultant.ru. 